\title{
Insulin-like growth factor-I induces chemoresistence to docetaxel by inhibiting miR-143 in human prostate cancer
}

\author{
Xiao-Bing Niu ${ }^{1,2,3 *}$, Guang-Bo Fu' ${ }^{1,3, *}$ Lin Wang ${ }^{4, *}$, Xin Ge$^{1}$, Wei-Tao Liu ${ }^{1}$, Yi-Yang \\ Wen $^{1}$, Hao-Ran Sun ${ }^{1}$, Ling-Zhi Liu ${ }^{5}$, Zeng-Jun Wang ${ }^{2}$ and Bing-Hua Jiang ${ }^{1,5}$ \\ ${ }^{1}$ State Key Laboratory of Reproductive Medicine, Key Laboratory of Human Functional Genomics of Jiangsu Province, Jiangsu \\ Key Laboratory of Cancer Biomarkers, Prevention, and Treatment Department of Pathology, Cancer Center, Nanjing Medical \\ University, Nanjing, China \\ ${ }^{2}$ Department of Urology, The First Affiliated Hospital of Nanjing Medical University, Nanjing, China \\ ${ }^{3}$ Department of Urology, Huai'an First People's Hospital, Nanjing Medical University, Huai'an, China \\ ${ }^{4}$ Institute of Medical and Pharmaceutical Sciences, The Academy of Medical Sciences, Zhengzhou University, Zhengzhou, \\ China \\ ${ }^{5}$ Department of Pathology, Carver College of Medicine, The University of Iowa, Iowa City, IA, USA \\ * These authors have contributed equally to this work \\ Correspondence to: Bing-Hua Jiang, email: binghjiang@yahoo.com \\ Zeng-Jun Wang, email: zengjunwang2002@sina.com \\ Keywords: prostate cancer; docetaxel; miR-143; IGF-l; tumor growth
}

Received: January 31, $2017 \quad$ Accepted: September 15, $2017 \quad$ Published: November 09, 2017

Copyright: Niu et al. This is an open-access article distributed under the terms of the Creative Commons Attribution License 3.0 (CC BY 3.0), which permits unrestricted use, distribution, and reproduction in any medium, provided the original author and source are credited.

\section{ABSTRACT}

Elevated levels of insulin-like growth factor-I (IGF-I) are associated with carcinogenesis and cancer progression. However, the molecular mechanisms by which IGF-I promotes prostate cancer development remain to be elucidated. Docetaxel chemotherapy is an important therapeutic strategy in many types of human cancers including prostate cancer. In this study, we showed that IGF-I rendered PC-3 and DU145 cells more resistant to docetaxel treatment. IGF-I treatment decreased miR143 expression, but increased the expression levels of IGF-I receptor (IGF-IR) and insulin receptor substrate 1 (IRS1), direct targets of miR-143. Overexpression of miR-143 abolished IGF-I-induced chemoresistance to docetaxel treatment, decreased expression levels of IGF-I, IRS1, and vascular endothelial growth factor (VEGF) in prostate cancer cell lines. Furthermore, docetaxel treatment significantly inhibited VEGF transcriptional activation, whereas IGF-I treatment induced VEGF transcriptional activation in a dose-dependent manner. Forced expression of IGF-IR and IRS1 CDNAs without the 3' UTR regions restored miR-143-inhibited VEGF transcriptional activation. Finally, miR-143 inhibited tumor growth and made cells more sensitive to docetaxel treatment for decreasing tumor growth in vivo. Taken together, our data demonstrates that IGF-I induces docetaxel resistance and upregulates IGF-IR and IRS1 expression through miR-143 downregulation, whereas miR-143 acts as a tumor suppressor by targeting its targets IGF-IR and IRS1.

\section{INTRODUCTION}

Prostate cancer (PC) is the second leading cause of cancer death among men in the United States and the fourth most common tumor type worldwide [1,2]. Surgery, radiation and chemotherapy are generally effective for the majority of patients, but the prognosis of PC remains poor in patients with progressive disease. Docetaxel is widely used as a first-line drug for chemotherapy, but cell resistance to docetaxel is a hindrance for PC treatment. Thus, further understanding the molecular mechanism in promoting $\mathrm{PC}$ resistance to docetaxel is important 
and helpful for providing novel potential targets for PC treatment.

MicroRNAs (miRs) are a class of 19-22 nucleotide single-stranded small RNAs and act as major regulators of protein levels through either protein degradation or translational inhibition through binding to the 3 'UTR of target mRNA [3-6]. In human approximately 2,8645 unique mature miRNAs have been identified (http://mirdb.org/miRDB/). MiRNAs are known to be involved in a variety of biological processes, including development, differentiation, apoptosis, and cell proliferation [7]. As a result, miRNAs may function as either tumor suppressors or oncogenes. It has been demonstrated that miR-143 is a tumor suppressor in several types of cancer including prostate, breast and colorectal cancer [8-10]. To date, some genes including K-RAS, ELK1，IGF-IR, IRS1, Bcl-2 and ERK5 have been identified as direct targets of miR-143 [11-17]. In addition, by directly targeting protein-coding genes, miRNAs are capable to inhibit genes that are necessary for signaling pathways or drug-induced apoptosis to confer drug resistance. Up to now, multiple miRNAs have been found to be critical in the control of cancer drug resistance in PC. For example, downregulation of miR-205 and miR-31 promotes resistance by inhibiting chemotherapy-induced apoptosis in PC cells. It was reported that miR-148a attenuates paclitaxel resistance in PC3 cells by regulating MSK1 expression [18, 19].

Insulin-like growth factor (IGF) axis is one of the most investigated targets in cancer research due to the overexpression of its receptor in several types of human cancer including $\mathrm{PC}$, and targeting IGF axis showed promising anti-tumor capabilities in preclinical studies [20]. In this study, we found that IGF-I rendered PC cells more resistant to docetaxel treatment. We also demonstrated that IGF-I downregulated miR-143 and upregulated IGF-IR and IRSI, the well-known oncogenes in carcinogenesis. Angiogenesis is important for tumor growth, angiogenesis, metastasis and drug resistance, and vascular endothelial growth factor (VEGF) is one of the strongest angiogenesis factors. Moreover, we demonstrated that miR-143 suppressed IGF-I-induced IGF-IR, IRS1, and VEGF expression and enhanced sensitivity to docetaxel treatment in the presence of IGF-I. Forced expression of IGF-IR and IRS1 restored miR-143inhibited VEGF transcriptional activation. Finally, miR143 inhibited tumor growth and increased sensitivity of PC to docetaxel and IGF-1 treatment in vivo. Our results reveal a novel mechanism of miR-143 in docetaxel resistance in $\mathrm{PC}$, which is useful for developing new mechanism-based treatment option for PC in the future.

\section{RESULTS}

\section{IGF-I promoted chemoresistance to docetaxel treatment in PC cells}

Docetaxel is used as a standard first-line drug for chemotherapy and is shown to have a survival advantage in metastatic castration-resistant PC (mCRPC) with two to three months of median survival advantage and improved life quality when compared to mitoxantrone treatment $[21,22]$. Here we found that IGF-I increased resistance of PC-3 cells and DU145 cells to docetaxel treatment (Figure $1 \mathrm{~A}$ and $1 \mathrm{~B}$ ), indicating that IGF-I axis may be involved in mediating docetaxel resistance in PC cells.

\section{IGF-I treatment induced IGF-IR and IRS1 expression in PC cells}

Next, we found that IGF-I significantly decreased the expression levels of miR-143 in PC-3 and DU145 cells by $50 \%$ (Figure 2A). IGF-IR and IRS1 have been reported as direct targets of miR-143 [14, 15]. Consistent
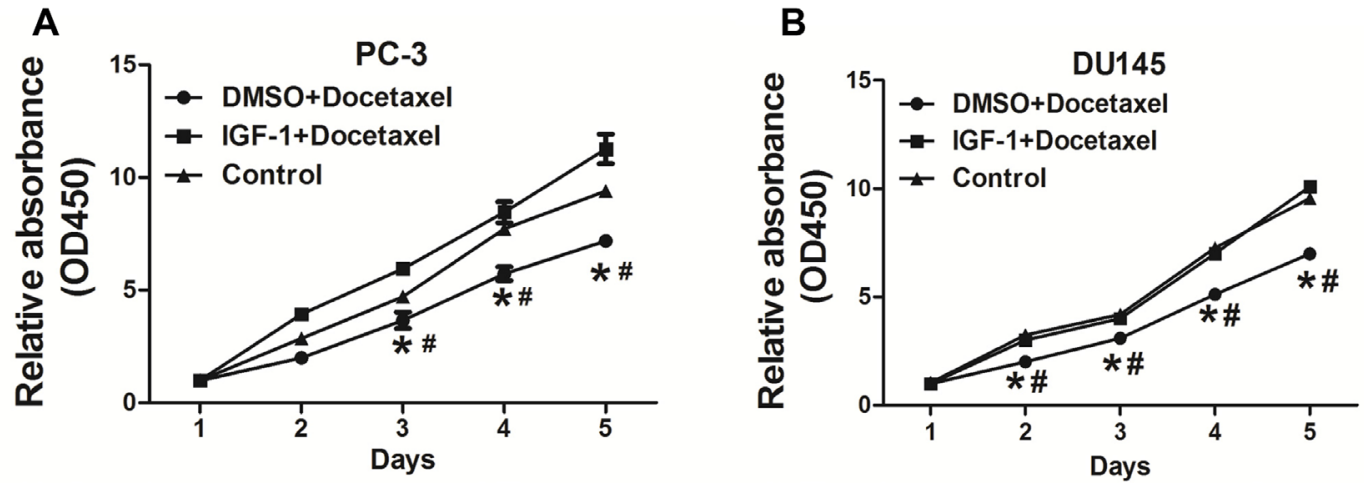

Figure 1: IGF-I promoted chemoresistance to docetaxel treatment in PC cells. (A) PC-3 cells were treated with 10nM docetaxel, then cell proliferation was analyzed using CCK8 assay. The results showed that IGF-I promoted chemoresistance to docetaxel in PC-3 cells. (B) Similar experiments were performed using DU145 cells, and IGF-I also enhanced chemoresistance to docetaxel in DU145 cells. Data represent mean \pm SD. of three replicates. ${ }^{*} P<0.05$ when compared to Control, ${ }^{\#} P<0.05$ when compared to IGF-I plus docetaxel treatment. 
A

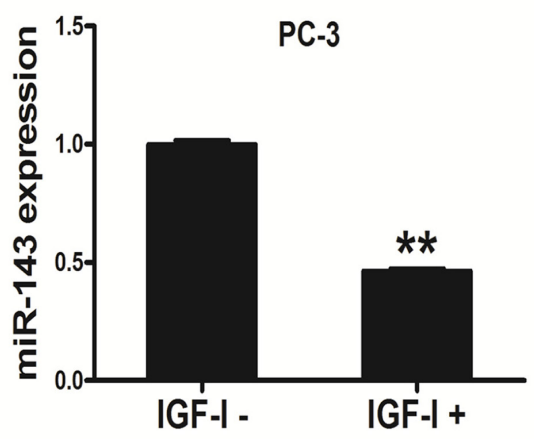

B

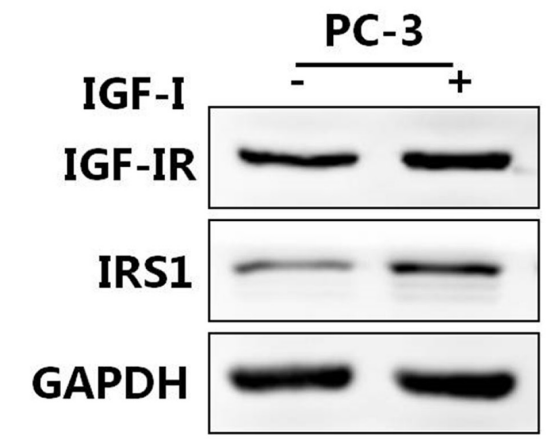

C

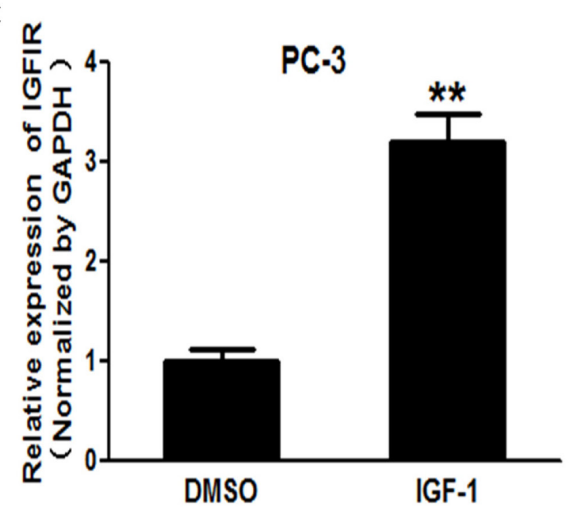

D

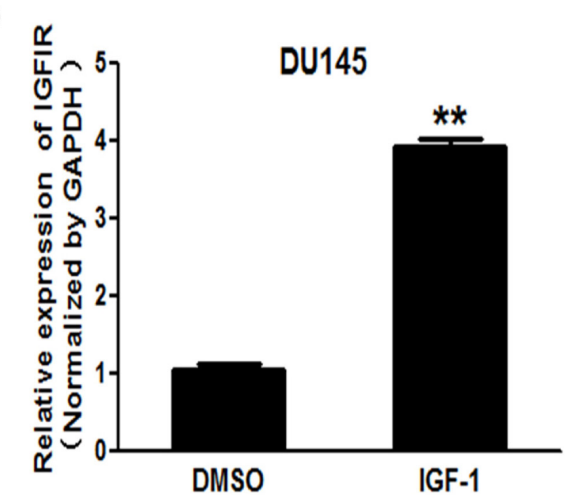

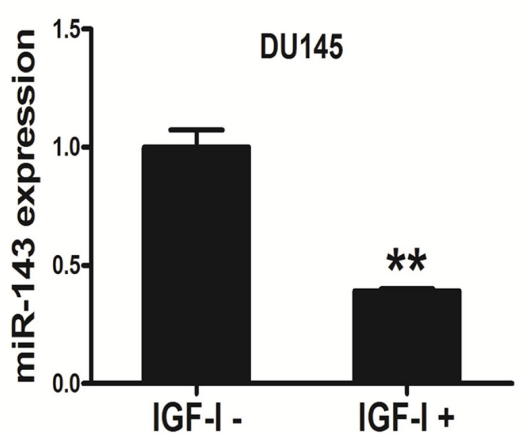
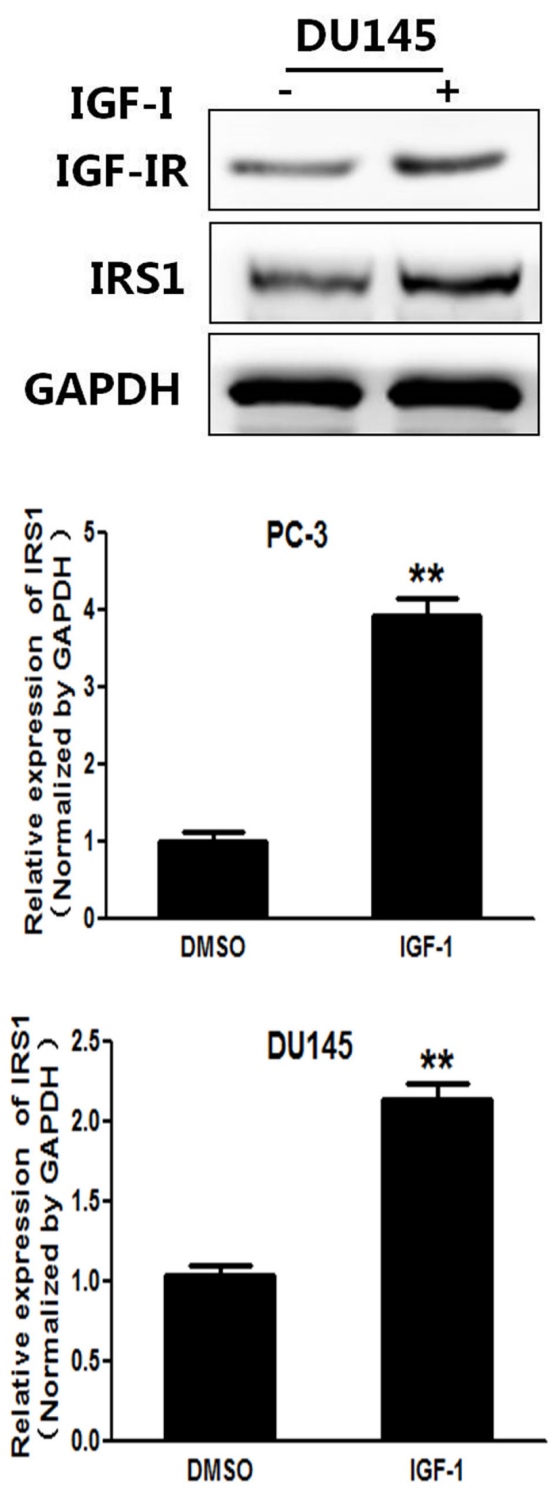

Figure 2: IGF-I induced expression levels of IGF-IR and IRS1 in prostate cancer cells. (A) PC-3 cells were treated with IGF-I, then the expression of miR-143 was analyzed by RT-qPCR. The results showed that IGF-I treatment decreased miR-143 expression in PC-3 and DU145 cells. (B) PC-3 and DU145 cells were treated with IGF-I at $200 \mathrm{ng} / \mathrm{ml}$ or solvent control for $4 \mathrm{~h}$, the expression of IGFIR, IRS1 and GAPDH was determined using Western blotting. (C) PC-3 cells were treated with IGF-IR, and the mRNA levels of IGF-IR and IRS1 were analyzed using RT-qPCR and normalized by GAPDH expression. (D) Similar experiments were performed using DU145 cells treated with IGF-I. Data represent mean \pm SD. of three replicates. ${ }^{* *}$ indicates significant difference at $P<0.01$. 
A
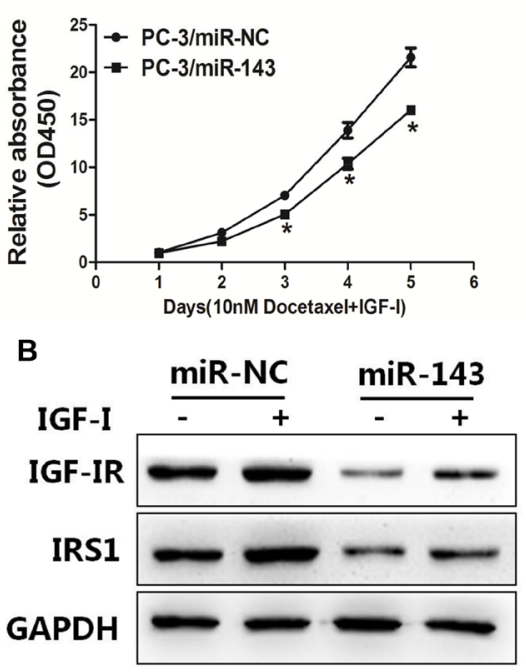

C
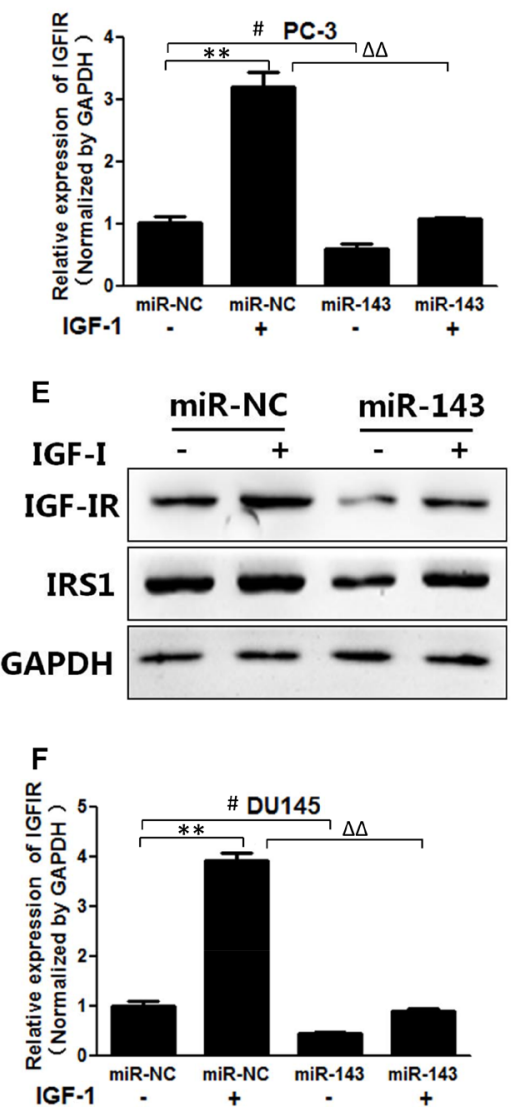

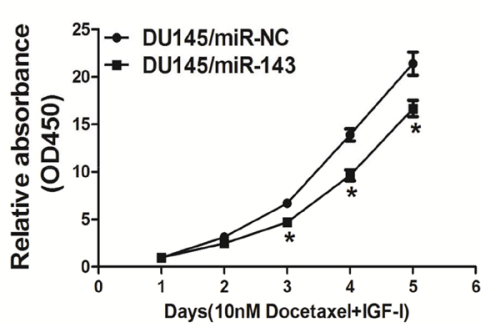

D
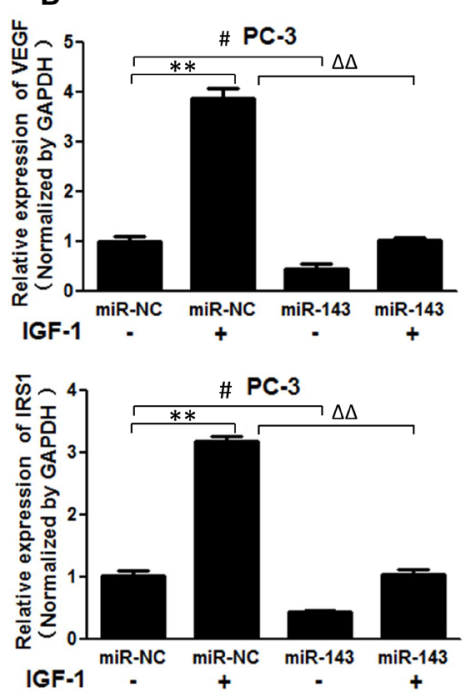

G
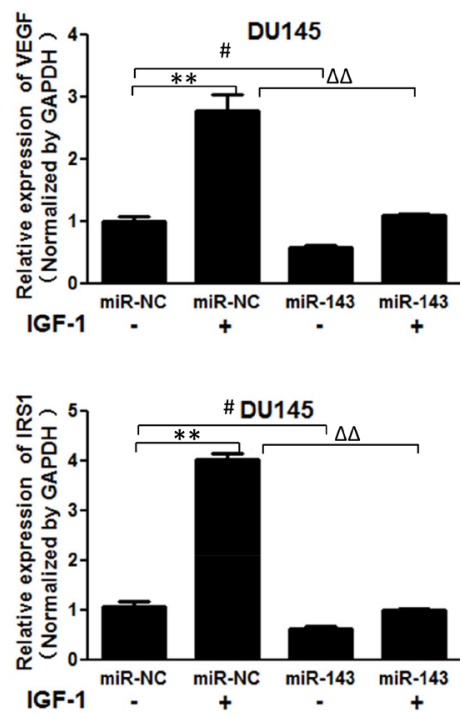

Figure 3: MiR-143 abolished IGF-I-induced IGF-IR, IRS1 expression, VEGF transcriptional activation and chemoresistance in PC cells. (A) PC-3 and DU145 cells stably expressed with miR-143 or miR-NC were treated with IGF-I and docetaxel as above. Cell proliferation assay was performed using CCK8 assay. (B) PC-3 cells were transfected with miR-143 or miRNC. Then the cells were treated with IGF-I or solvent control for $4 \mathrm{~h}$. The expression of IGF-IR, IRS1 and GAPDH was assayed using Western blotting. (C) The expression levels of IGF-IR and IRS1 in cells treated as above were tested using RT-qPCR and normalized to the expression levels of GAPDH. (D) The expression levels of VEGF were tested using RT-qPCR and normalized to the expression levels of GAPDH. (E-G) DU145 cells overexpressing miR-143 and miR-NC were treated as above, and the expression of IGF-IR and IRS1 at protein and mRNA levels was determined using Western blotting and RT-qPCR assays as above. The expression of VEGF was also detected using RT-qPCR. Data represent mean \pm SD. of three replicates. ${ }^{* *} P<0.01$ when compared to IGF-I treatment without miR-143 overexpression; ${ }^{\#} P<0.05$ when compared to miR-143 overexpression without IGF-I Treatment; ${ }^{\Delta} P<0.01$ when compared to miR-143 overexpression upon IGF-I treatment. 
with the downregulation of miR-143, IGF-I treatment markedly induced expression of IGF-IR and IRS1 at both protein (Figure 2B) and mRNA levels in PC-3 and DU145 cells (Figure 2C and 2D). The activation of IGFIR by binding to IGF-I leads to activation of numerous downstream pathways including PI3K/AKT and Raf/ MAPK pathways. Insulin receptor substrate 1 (IRS1) is one of the main signal transmitters from IGF-IR to the downstream pathways [23]. Given the important role of IGF-IR and IRS1 in drug resistance [24, 25], these results suggest that miR-143 and its targets IGF-IR and IRS may be involved in IGF-I-induced docetaxel resistance in PC cells.

\section{MiR-143 suppressed IGF-I-induced chemoresistance to docetaxel treatment, and decreased expression of IGF-IR and IRS1, and VEGF transcriptional activation in PC cells}

Our previous studies have demonstrated that miR-143 acts as a tumor suppressor to inhibit tumor growth, angiogenesis and increases the anti-cancer effects of oxaliplatin and temozolomide [14, 15, 26]. To further study the effect of miR-143 in regulating signal molecules, we found that miR-143 overexpression increased sensitivity to docetaxel treatment in PC cells

A

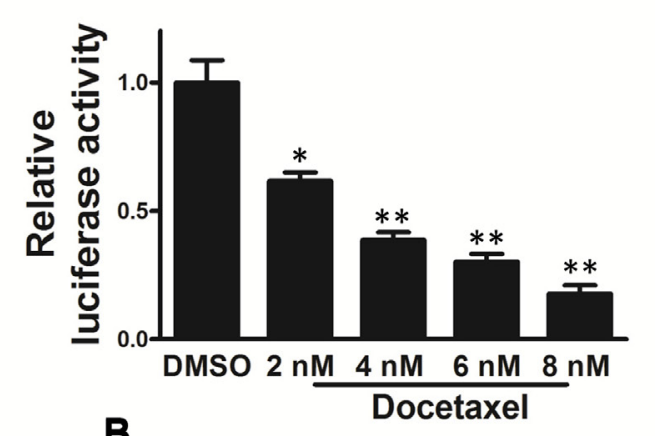

B

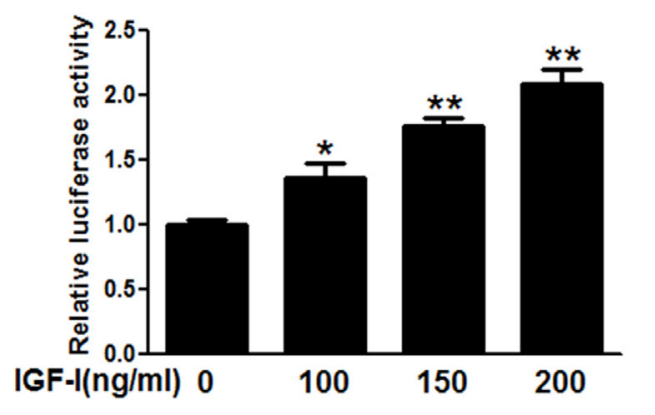

in the presence of IGF-I (Figure 3A). IGF-I treatment upregulated IGF-IR and IRS1 expression in PC-3 cells, whereas overexpression of miR-143 inhibited IGF-Iinduced IGF-IR and IRS1 expression (Figure 3B and $3 C)$. VEGF is a vital angiogenesis factor during tumor angiogenesis, which exhibits an important role in tumor initiation, cancer development and chemoresistance [27, 28]. Forced expression of miR-143 also decreased IGF-Ienhancing VEGF mRNA levels in PC-3 cells (Figure 3D). Similar results were obtained using DU145 cells, showing that IGF-I increased IGF-IR, IRS1 and VEGF expression, and miR-143 attenuated protein levels of IGF-IR and IRS1 and mRNA levels of VEGF with or without IGF-I treatment (Figure 3E-3G), confirming the inhibitory effect of miR-143 on these signaling molecules. The results suggest that miR-143 enhances response to docetaxel treatment and reversed IGF-I-induced chemoresistance in PC cells.

\section{IGF-IR and IRS1 were downstream targets of miR-143 to inhibit VEGF transcriptional activation}

VEGF is essential for endothelial cell function associated with angiogenesis. In this study, docetaxel treatment reduced transcriptional activity of VEGF in
C

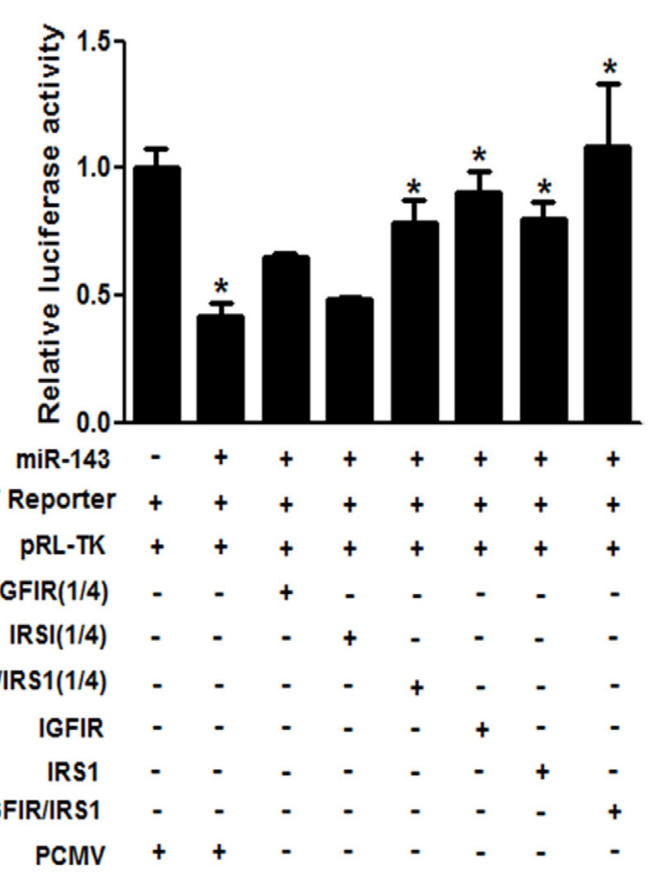

Figure 4: IGF-IR and IRS1 were two key downstream targets of miR-143 to inhibit VEGF transcriptional activation. (A) PC-3 cells were treated with docetaxel at different concentration and cultured for $48 \mathrm{~h}$, the transcriptional activation of VEGF was determined using luciferase assay. (B) PC-3 cells were treated with IGF-I at $200 \mathrm{ng} / \mathrm{ml}$ for $16 \mathrm{~h}$ and subjected to VEGF luciferase assay as above. (C) PC-3 cells stably expressing miR-143 or miR-NC were co-transfected with VEGF reporter, pRL-TK vector plasmid without or with IGF-IR or IRS1 cDNA plasmid at $50 \mathrm{ng}(1 / 4$ dose) or $200 \mathrm{ng}$ (1 dose, without indication). The relative luciferase activities of VEGF reporter were assayed and calculated by the ratios of firefly/Renilla luciferase activities, which were normalized to that of the control. Data represent mean $\pm \mathrm{SD} .{ }^{*}$ indicates significant difference at $P<0.05 ;{ }^{* *}$ indicates significant difference at $P<0.01$. 
PC-3 cells (Figure 4A). IGF-I treatment increased VEGF transcriptional activity in PC-3 cells in a dose-dependent manner (Figure 4B). PC-3 cells stably expressing miR143 or negative control were co-transfected with VEGF promoter reporter, $\mathrm{pRL}$-TK vector plasmid without or with IGFIR or IRS1 cDNA plasmid at $50 \mathrm{ng}(1 / 4$ dose) or 200 ng $(1$ dose). The relative luciferase activities of VEGF reporter were assayed and calculated by the ratios of firefly/Renilla luciferase activities, which were normalized to that of the control (Figure 4C). The results showed that miR-143 overexpression decreased VEGF transcriptional activation to $45 \%$, whereas forced expression of IGFIR or IRS1 alone was sufficient to rescue miR-143inhibiting VEGF transcriptional activity. Furthermore, the combination of IGF-IR and IRS1 at low concentration (1/4 dose each) significantly restored the VEGF transcriptional activation. The results demonstrate that IGF-IR and IRS1 are two key downstream mediators of miR-143 to attenuate VEGF transcriptional activation.

\section{MiR-143 inhibited tumor growth in vivo}

We next investigated the effect of miR-143 on tumor growth of PC-3 cells using nude mice. PC-3 cells stably expressing miR-NC or miR-143 were subcutaneously injected into male BALB/cA nude mice to study tumor growth. The results showed that miR-143 significantly attenuated tumor growth with decreased tumor size and weight (Figure 5A-5C). In agree with the results from in vitro experiments above, the expression levels of IGFIR, IRS1 and VEGF from the tumor tissues of miR-143 expressing group were lower than those from miR-NC
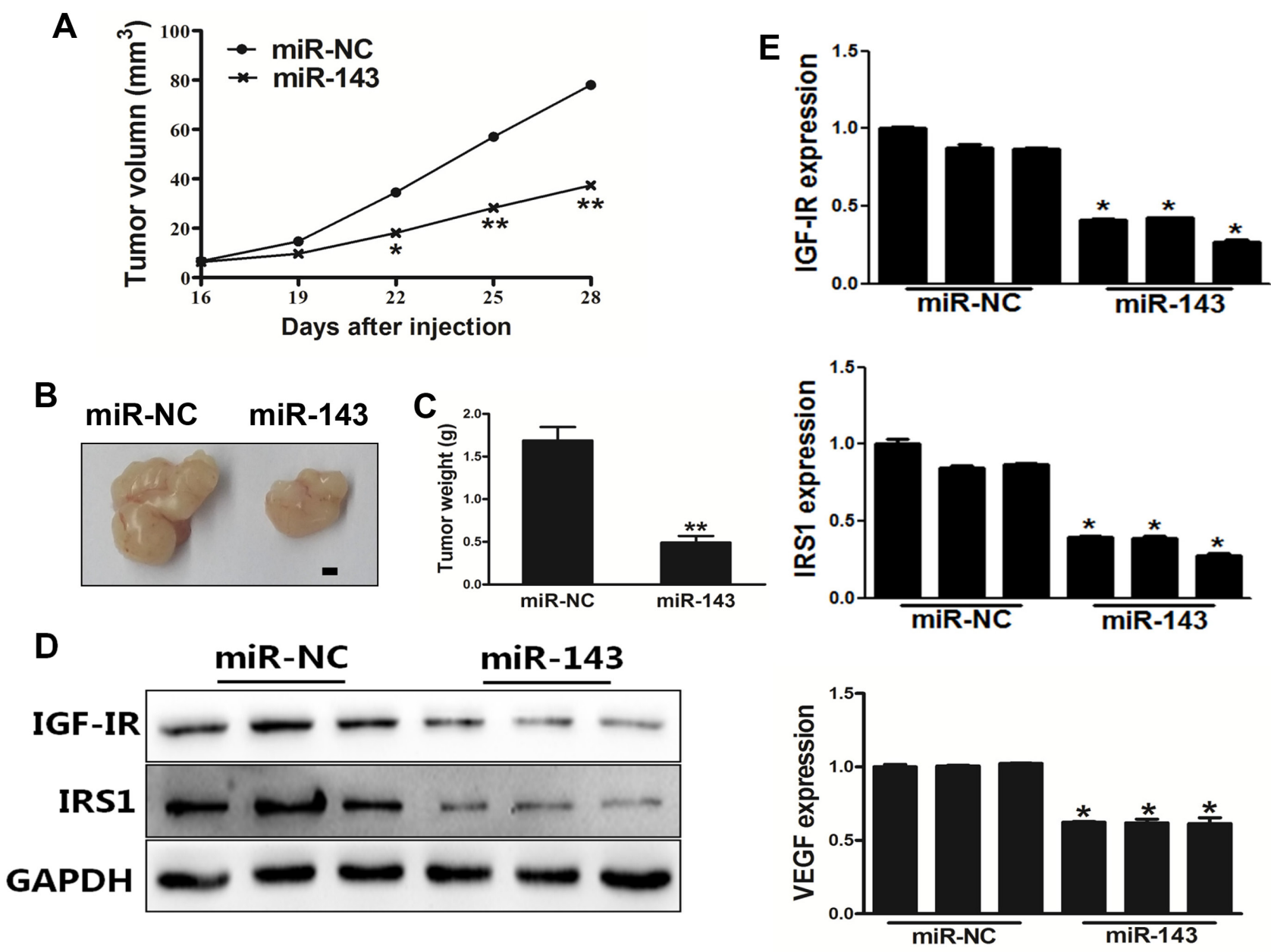

Figure 5: MiR-143 inhibited tumor growth in vivo. (A) PC-3 cells were transduced with lentivirus carrying miR-143 or miR-NC and selected using puromycin. Cells stably expressing miR-143 or miR-NC at $5 \times 10^{6}$ were subcutaneously injected into both flanks of male BALB/cA nude mice. Tumor volumes were monitored over time as indicated. (B) After 28 days post implantation, the xenografts were harvested and photographed. Representative pictures from each group were shown. Bar $=2 \mathrm{~mm}$. (C) The tumors from each group were weighed and the results showed miR-143 overexpression decreased tumor size and weight in vivo. (D) Total proteins were assayed by Western blotting to determine levels of IGF-IR and IRS1. Levels of GAPDH were used as internal control. (E) Total RNAs were isolated and assayed by qRT-PCR to determine the expression of IGF-IR, IRS1 and VEGF in tumors. Data represent mean \pm SD. ${ }^{*}$ indicates significant difference at $P<0.05 ;{ }^{* *}$ indicates significant difference at $P<0.01$. 
group (Figure 5D-5E), demonstrating that miR-143 acts as a tumor suppressor to inhibit tumor growth in PC cells, and IGF-IR and IRS1 are targets of miR-143 in vivo.

\section{MiR-143 sensitized PC cells to docetaxel treatment in vivo}

Finally, in order to study whether miR-143 sensitize PC cells to docetaxel and IGF-I treatment, PC-3 cells stably expressing miR-143 or miR-NC were subcutaneously injected into both flanks of male BALB/ cA nude mice. IGF-I (200 ng/ml) and docetaxel (10 nM) was added 14 day later by peritoneal injection. After 28 days post implantation, the xenografts were harvested and photographed (Figure 6A-6B). The results showed that miR-143 overexpression further increased docetaxel effect for inhibiting tumor volume and weight in vivo (Figure 6A-6C). As expected, expression levels of VEGF in tumor tissues from miR-143 expressing group were significantly lower than those from miR-NC group (Figure 6D). Thus,

A

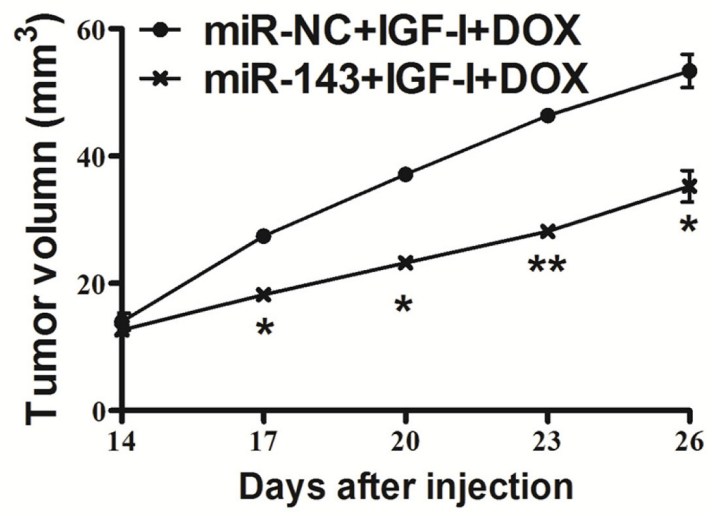

C

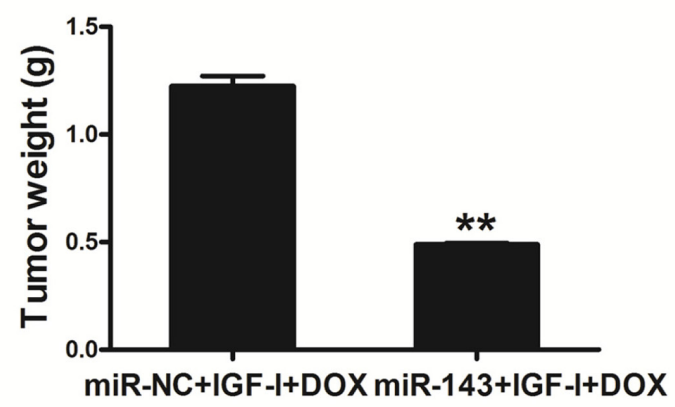

these results indicate that miR-143 renders PC cells more sensitive to docetaxel treatment in vivo.

\section{DISCUSSION}

$\mathrm{PC}$ is one of the most common cancers in males. However, the molecular mechanisms of PC progression and drug resistance are still to be uncovered. Growing evidence has shown that miRNAs are dysregulated and involved in cancer progression, and some of miRNAs may be potential targets in cancer diagnosis and treatment [29]. MiRNAs have shown multiple roles of in PC pathogenesis and are associated with the initiation and progression of PC $[30,31]$. Among the identified tumor-suppressing miRNAs, miR-143 has been well studied in human PC $[10,32,33]$. Docetaxel is a common chemotherapeutic agent used to treat multiple malignancies including PC. However, there are no good biomarkers of response/resistance known for docetaxel treatment. Molecular profiling of miRNAs may be helpful for developing molecular diagnostics and
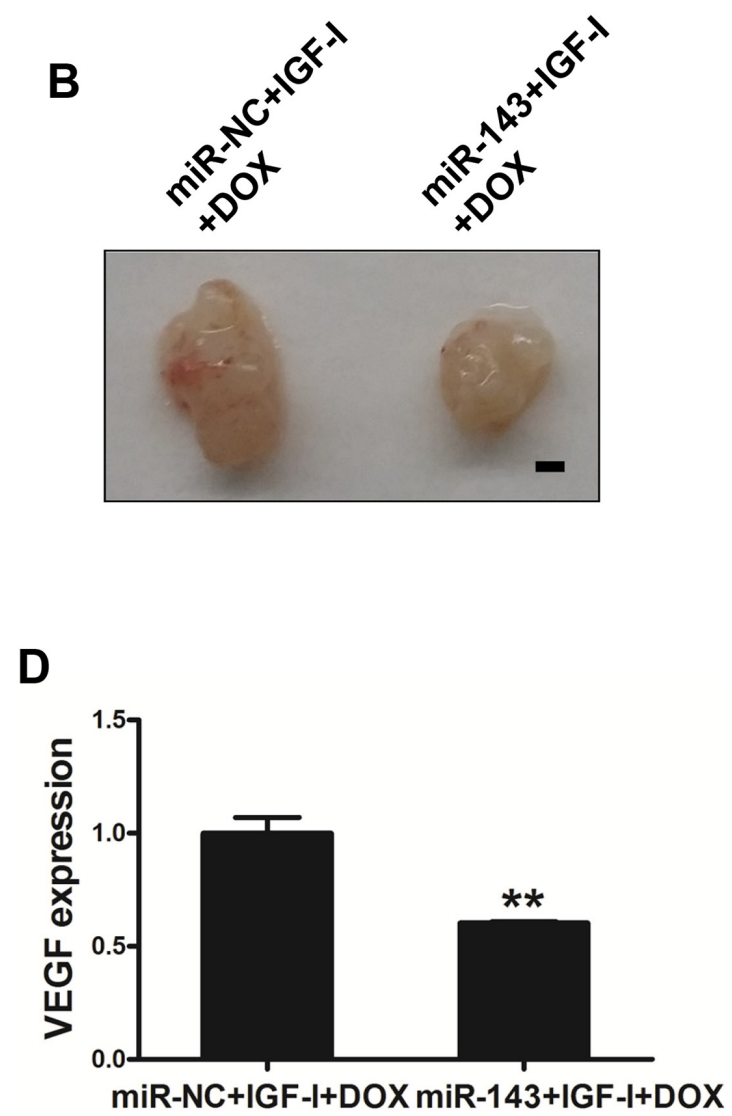

Figure 6: MiR-143 sensitized the PC cells to docetaxel treatment in vivo. (A) PC-3 cells stably expressing miR-143 or miR$\mathrm{NC}$ at $5 \times 10^{6}$ cells were subcutaneously injected into both flanks of male BALB/cA nude mice. Tumor volume was monitored over time as indicated, then IGF-I $(200 \mathrm{ng} / \mathrm{ml})$ and docetaxel $(10 \mathrm{nM})$ was administrated by peritoneal injection. (B) After 28 days post implantation, the xenografts were harvested and photographed. Representative pictures from each group were shown. Bar=2 mm. (C) The tumors from each group were weighed and the results showed miR-143 overexpression decreased tumor weight in vivo. (D) Total RNAs were isolated and assayed by RT-qPCR to determine the expression of VEGF in tumors. Data represent mean \pm SD. ${ }^{*}$ indicates significant difference at $P<0.05 ;{ }^{* *}$ indicates significant difference at $P<0.01$. 
identifying subgroups of patients destined to respond to docetaxel, and also for better understanding the molecular mechanisms of chemoresistance $[34,35]$.

Recently, several studies have demonstrated that IGF-I is associated with an increased risk of developing several types of cancers including lung, breast, colorectal, and PC [36-39]. IGF-IR and IRS1 have been reported as direct targets of miR-143. However, the role and underlying mechanism of miR-143 in mediating docetaxel resistance in $\mathrm{PC}$ remain elusive.

In the present study, we found that IGF-I- and its ligand IGF-IR-mediated signal molecules were often upregulated in PC, efficiently rendered PC-3 and DU145 cells more resistant to docetaxel treatment. IGF-I decreased miR-143 and increased its targets IGF-IR and IRS1 expression levels. Moreover, miR-143 inhibited VEGF transcriptional activation through IGF-IR and IRS1, and suppressed IGF-I-induced chemoresistance to docetaxel treatment. Finally, miR-143 inhibited tumor growth and increased sensitivity of PC to docetaxel and IGF-I treatment in vivo. In summary, we report here that IGF-I induces chemoresistence to docetaxel treatment in PC, and miR-143 and its targets IGF-IR and IRS1 are involved in this process.

\section{MATERIALS AND METHODS}

\section{Cell culture and reagents}

Human PC cells PC-3 and DU145 were maintained in RPMI1640 medium, and human embryonic kidney 293T (HEK-293T) cells were cultured in DMEM medium, supplemented with $10 \%$ fetal bovine serum, 100 units $/ \mathrm{ml}$ penicillin, and $100 \mu \mathrm{g} / \mathrm{ml}$ streptomycin. Cells were cultured in humidified $5 \% \mathrm{CO}_{2}$ incubator at $37^{\circ} \mathrm{C}$. Recombinant human IGF-I were purchased from Sigma (St louis, MO, USA).

\section{Lentiviral packaging and stable cell line establishment}

Lentivirus carrying miR-143 and miR-NC (negative control) were packaged in HEK-293T cells using lentiviral packaging kit following the manufacturer's instructions (Open Biosystems, AL, USA). Stable cell lines PC-3/ miR-143 and PC-3/miR-NC were established by lentiviral transduction in the presence of polybrene and screened by puromycin (Sigma, MI, USA).

\section{Cell proliferation assay}

Cells were seeded in 96-well plates at confluence of 2000 cells per well. The capability of cell proliferation was measured using a CCK8 kit (Dojindo Laboratories, Kumamoto, Japan) according to the manufacturer's instruction at different indicated time points. Data were from three separate experiments with six replications each time.

\section{RNA isolation and quantitative real-time PCR (qPCR)}

Total RNAs of cells were extracted using TRIzol reagent (Invitrogen, CA, USA) according to the manufacturer's instruction. To test miR-143 expression, expression of U6 was used as an endogenous control. To determine expression of miR-143 forward primer: GCTCGTCGAGATAAGCTGTGTG; reverse primer: GTTCGCTGAGATGAAGCACTG. To determine the mRNA levels of VEGF, total RNAs were reversely transcribed by oligodT primer using PrimeScript RT Reagent Kit (Vazyme, Nanjing, China). Housekeeping gene GAPDH was used as internal control. The cDNAs were amplified by qPCR using AceQ SYBR Master Mix (Vazyme, Nanjing, China) on a 7900HT system. Relative fold changes in expression of the target gene transcripts were determined using the comparative cycle threshold method $\left(2^{-\Delta \Delta C t}\right)$.

\section{Protein extraction and western blotting}

Cells or grounded tissues were lysed on ice for 30 min in RIPA buffer (150 mMNaCl, $100 \mathrm{mM}$ Tris, $\mathrm{pH} 8.0$, $0.1 \%$ SDS, $1 \%$ Triton X-100, 1\% sodium deoxycholate, $5 \mathrm{mM}$ EDTA and $10 \mathrm{mM} \mathrm{NaF}$ ) supplemented with $1 \mathrm{mM}$ sodium vanadate, $2 \mathrm{mM}$ leupeptin, $2 \mathrm{mM}$ aprotinin, $1 \mathrm{mM}$ phenylmethylsulfonyl fluoride (PMSF), $1 \mathrm{mM}$ DTT, and 2 $\mathrm{mM}$ pepstatin $\mathrm{A}$. The lysates were centrifugated at 12,000 rpm $4{ }^{\circ} \mathrm{C}$ for $15 \mathrm{~min}$, and the supernatants were collected. The protein concentration was determined using BCA assay (Beyotime Institute of Biotechnology, Jiangsu, China). Protein extracts were separated by SDS-polyacrylamide gel electrophoresis (SDS-PAGE), and transferred to nitrocellulose membranes in transfer buffer (20mM Tris, $150 \mathrm{mM}$ glycine and 20\% (v/v) methanol). Membranes were blocked with $5 \%$ nonfat dry milk in $1 \times$ PBS containing $0.05 \%$ Tween-20 and incubated with antibodies against IGFIR, IRS1 and GAPDH. Antibodies against IGF-IR and IRS1 were purchased from Cell Signaling Technology (Beverly, MA, USA). GAPDH antibody was from Bioworlde. The protein bands were probed with secondary antibody IgG conjugated to horseradish peroxidase, and visualized with the SuperSignal West Pico Chemiluminescent Substrate Kits (Thermo Scientific, MA, USA).

\section{Luciferase assays}

For plasmid transient transfection, PC-3 cells stably expressing miR-143 or negative control were cotransfected with VEGF reporter [40], pRL-TK vector plasmid without (pCMV6 vector alone) or with pCMV6IGF-IR or pCMV6-IRS1 plasmid (OriGene Technologies, 
Rockville, USA) at $50 \mathrm{ng}$ (1/4 dose) or $200 \mathrm{ng}$ (1 dose) using Lipofectamine 2000 (Invitrogen, Carlsbad, USA). Firefly luciferase (Luc) and Renilla luciferase activities were measured using a dual luciferase assay kit (Promega, Madison, USA). Each experiment was repeated three times with three replicates.

\section{Xenograft studies}

For tumor growth assay, male nude mice [BALB/ cA-nu (nu/nu), 6-week-old] were purchased from Shanghai Laboratory Animal Center (Chinese Academy of Sciences, Shanghai, China), and animals were maintained under special pathogen-free (SPF) conditions. Aliquots of cells $\left(5 \times 10^{6}\right)$ were suspended in $150 \mu \mathrm{L}$ of FBS-free RPMI 1640 medium and subcutaneously injected into each side of the posterior flank of nude mice. Tumor size was measured using vernier caliper every 2 days when they became visible, and the tumor volume was calculated according to the formula: Volume $=0.5 \times$ Length $\times$ Width2. For chemoresistant effects of miR-143 in vivo, 14 days after implantation, IGF-I $(200 \mathrm{ng} / \mathrm{ml})$ and docetaxel $(10 \mathrm{nM})$ were intraperitoneal injected into mice for docetaxel and IGF-I-treatment.

\section{Statistical analysis}

All experiments were performed in triplicate, and data were analyzed with GraphPad Prism 5 (La Jolla, CA, USA). Statistical evaluation for data analysis was determined by student t-test. $P<0.05$ was considered as statistically significant.

\section{ACKNOWLEDGMENTS}

This work is supported by grant from the National Natural Science Foundation of China $(81270685$, 81472944, 81320108019), the Project Funded by the Priority Academic Program Development of Jiangsu Higher Education Institutions (JX10231802) and the Project Funded by the Huaian Science and Technology Bureau(HAS2015014).

\section{CONFLICTS OF INTEREST} interest.

The authors declare that they have no competing

\section{REFERENCES}

1. Cancer Genome Atlas Research N. The Molecular Taxonomy of Primary Prostate Cancer. Cell. 2015; 163:1011-25.

2. Siegel RL, Miller KD, Jemal A. Cancer statistics, 2015. CA Cancer J Clin. 2015; 65:5-29.

3. Carthew RW, Sontheimer EJ. Origins and Mechanisms of miRNAs and siRNAs. Cell. 2009; 136:642-55.
4. Pan Q, Chegini N. MicroRNA signature and regulatory functions in the endometrium during normal and disease states. Semin Reprod Med. 2008; 26:479-93.

5. Wu S, Huang S, Ding J, Zhao Y, Liang L, Liu T, Zhan $\mathrm{R}$, He X. Multiple microRNAs modulate p21Cip1/Waf1 expression by directly targeting its 3 ' untranslated region. Oncogene. 2010; 29:2302-08.

6. Zhang L, Stokes N, Polak L, Fuchs E. Specific microRNAs are preferentially expressed by skin stem cells to balance self-renewal and early lineage commitment. Cell Stem Cell. 2011; 8:294-308.

7. Huang Y, Shen XJ, Zou Q, Wang SP, Tang SM, Zhang GZ. Biological functions of microRNAs: a review. J Physiol Biochem. 2011; 67:129-39.

8. Yang F, Xie YQ, Tang SQ, Wu XB, Zhu HY. miR-143 regulates proliferation and apoptosis of colorectal cancer cells and exhibits altered expression in colorectal cancer tissue. Int J Clin Exp Med. 2015; 8:15308-12.

9. Yang Z, Chen D, Nie J, Zhou S, Wang J, Tang Q, Yang X. MicroRNA-143 targets CD44 to inhibit breast cancer progression and stem cell-like properties. Mol Med Rep. 2016; 13:5193-99.

10. Zhou P, Chen WG, Li XW. MicroRNA-143 acts as a tumor suppressor by targeting hexokinase 2 in human prostate cancer. Am J Cancer Res. 2015; 5:2056-63.

11. Akao Y, Nakagawa Y, Iio A, Naoe T. Role of microRNA-143 in Fas-mediated apoptosis in human T-cell leukemia Jurkat cells. Leuk Res. 2009; 33:1530-38.

12. Chen X, Guo X, Zhang H, Xiang Y, Chen J, Yin Y, Cai X, Wang K, Wang G, Ba Y, Zhu L, Wang J, Yang R, et al. Role of miR-143 targeting KRAS in colorectal tumorigenesis. Oncogene. 2009; 28:1385-92.

13. Cordes KR, Sheehy NT, White MP, Berry EC, Morton SU, Muth AN, Lee TH, Miano JM, Ivey KN, Srivastava D. miR-145 and miR-143 regulate smooth muscle cell fate and plasticity. Nature. 2009; 460:705-10.

14. He J, Qian X, Carpenter R, Xu Q, Wang L, Qi Y, Wang ZX, Liu LZ, Jiang BH. Repression of miR-143 mediates $\mathrm{Cr}$ (VI)-induced tumor angiogenesis via IGF-IR/IRS1/ERK/ IL-8 pathway. Toxicol Sci. 2013; 134:26-38.

15. Qian X, Yu J, Yin Y, He J, Wang L, Li Q, Zhang LQ, Li CY, Shi ZM, Xu Q, Li W, Lai LH, Liu LZ, Jiang BH. MicroRNA-143 inhibits tumor growth and angiogenesis and sensitizes chemosensitivity to oxaliplatin in colorectal cancers. Cell Cycle. 2013; 12:1385-94.

16. Suzuki HI, Yamagata K, Sugimoto K, Iwamoto T, Kato S, Miyazono K. Modulation of microRNA processing by p53. Nature. 2009; 460:529-33.

17. Zhang H, Cai X, Wang Y, Tang H, Tong D, Ji F. microRNA-143, down-regulated in osteosarcoma, promotes apoptosis and suppresses tumorigenicity by targeting Bcl-2. Oncol Rep. 2010; 24:1363-69.

18. Bhatnagar N, Li X, Padi SK, Zhang Q, Tang MS, Guo B. Downregulation of miR-205 and miR-31 confers resistance 
to chemotherapy-induced apoptosis in prostate cancer cells. Cell Death Dis. 2010; 1:e105.

19. Fujita Y, Kojima K, Ohhashi R, Hamada N, Nozawa Y, Kitamoto A, Sato A, Kondo S, Kojima T, Deguchi T, Ito M. MiR-148a attenuates paclitaxel resistance of hormone-refractory, drug-resistant prostate cancer PC3 cells by regulating MSK1 expression. J Biol Chem. 2010; 285:19076-84.

20. Heidegger I, Massoner P, Sampson N, Klocker H. The insulin-like growth factor (IGF) axis as an anticancer target in prostate cancer. Cancer Lett. 2015; 367:113-21.

21. Petrylak DP, Tangen CM, Hussain MH, Lara PN Jr, Jones JA, Taplin ME, Burch PA, Berry D, Moinpour C, Kohli M, Benson MC, Small EJ, Raghavan D, Crawford ED. Docetaxel and estramustine compared with mitoxantrone and prednisone for advanced refractory prostate cancer. $\mathrm{N}$ Engl J Med. 2004; 351:1513-20.

22. Tannock IF, de Wit R, Berry WR, Horti J, Pluzanska A, Chi KN, Oudard S, Théodore C, James ND, Turesson I, Rosenthal MA, Eisenberger MA, Investigators TA, and TAX 327 Investigators. Docetaxel plus prednisone or mitoxantrone plus prednisone for advanced prostate cancer. N Engl J Med. 2004; 351:1502-12.

23. Motallebnezhad M, Aghebati-Maleki L, Jadidi-Niaragh F, Nickho H, Samadi-Kafil H, Shamsasenjan K, Yousefi M. The insulin-like growth factor-I receptor (IGF-IR) in breast cancer: biology and treatment strategies. Tumour Biol. 2016; 37:11711-21.

24. Lamhamedi-Cherradi SE, Menegaz BA, Ramamoorthy V, Vishwamitra D, Wang Y, Maywald RL, Buford AS, Fokt I, Skora S, Wang J, Naing A, Lazar AJ, Rohren EM, et al. IGF-1R and mTOR Blockade: Novel Resistance Mechanisms and Synergistic Drug Combinations for Ewing Sarcoma. J Natl Cancer Inst. 2016; 108:108.

25. Lovly CM, McDonald NT, Chen H, Ortiz-Cuaran S, Heukamp LC, Yan Y, Florin A, Ozretić L, Lim D, Wang L, Chen Z, Chen X, Lu P, et al. Rationale for co-targeting IGF-1R and ALK in ALK fusion-positive lung cancer. Nat Med. 2014; 20:1027-34.

26. Wang L, Shi ZM, Jiang CF, Liu X, Chen QD, Qian X, Li DM, Ge X, Wang XF, Liu LZ, You YP, Liu N, Jiang BH. MiR-143 acts as a tumor suppressor by targeting N-RAS and enhances temozolomide-induced apoptosis in glioma. Oncotarget. 2014; 5:5416-27. https://doi.org/10.18632/ oncotarget.2116.

27. Epstein RJ. VEGF signaling inhibitors: more pro-apoptotic than anti-angiogenic. Cancer Metastasis Rev. 2007; 26:443-52.

28. Simons M, Gordon E, Claesson-Welsh L. Mechanisms and regulation of endothelial VEGF receptor signalling. Nat Rev Mol Cell Biol. 2016; 17:611-25.
29. Silber J, James CD, Hodgson JG. microRNAs in gliomas: small regulators of a big problem. Neuromolecular Med. 2009; 11:208-22.

30. Goto Y, Kurozumi A, Enokida H, Ichikawa T, Seki N. Functional significance of aberrantly expressed microRNAs in prostate cancer. Int J Urol. 2015; 22:242-252. https://doi. org/10.1111/iju.12700.

31. Wang YL, Wu S, Jiang B, Yin FF, Zheng SS, Hou SC. Role of MicroRNAs in Prostate Cancer Pathogenesis. Clin Genitourin Cancer. 2015; 13:261-70.

32. Kojima S, Enokida H, Yoshino H, Itesako T, Chiyomaru T, Kinoshita T, Fuse M, Nishikawa R, Goto Y, Naya Y, Nakagawa M, Seki N. The tumor-suppressive microRNA-143/145 cluster inhibits cell migration and invasion by targeting GOLM1 in prostate cancer. J Hum Genet. 2014; 59:78-87.

33. Wu D, Huang $\mathrm{P}$, Wang L, Zhou Y, Pan H, Qu P. MicroRNA-143 inhibits cell migration and invasion by targeting matrix metalloproteinase 13 in prostate cancer. Mol Med Rep. 2013; 8:626-30.

34. Puhr M, Hoefer J, Schäfer G, Erb HH, Oh SJ, Klocker H, Heidegger I, Neuwirt H, Culig Z. Epithelial-tomesenchymal transition leads to docetaxel resistance in prostate cancer and is mediated by reduced expression of miR-200c and miR-205. Am J Pathol. 2012; 181:2188-201.

35. Shi GH, Ye DW, Yao XD, Zhang SL, Dai B, Zhang HL, Shen YJ, Zhu Y, Zhu YP, Xiao WJ, Ma CG. Involvement of microRNA-21 in mediating chemo-resistance to docetaxel in androgen-independent prostate cancer PC3 cells. Acta Pharmacol Sin. 2010; 31:867-73.

36. Chan JM, Stampfer MJ, Giovannucci E, Gann PH, Ma J, Wilkinson P, Hennekens CH, Pollak M. Plasma insulinlike growth factor-I and prostate cancer risk: a prospective study. Science. 1998; 279:563-66.

37. Hankinson SE, Willett WC, Colditz GA, Hunter DJ, Michaud DS, Deroo B, Rosner B, Speizer FE, Pollak M. Circulating concentrations of insulin-like growth factor-I and risk of breast cancer. Lancet. 1998; 351:1393-96.

38. Ma J, Giovannucci E, Pollak M, Stampfer M. RESPONSE: Re: Prospective Study of Colorectal Cancer Risk in Men and Plasma Levels of Insulin-Like Growth Factor (IGF)-I and IGF-Binding Protein-3. J Natl Cancer Inst. 1999; 91:2052.

39. Yu H, Spitz MR, Mistry J, Gu J, Hong WK, Wu X. Plasma levels of insulin-like growth factor-I and lung cancer risk: a case-control analysis. J Natl Cancer Inst. 1999; 91:151-56.

40. Forsythe JA, Jiang BH, Iyer NV, Agani F, Leung SW, Koos RD, Semenza GL. Activation of vascular endothelial growth factor gene transcription by hypoxia-inducible factor 1 . Mol Cell Biol. 1996; 16:4604-13. 